\title{
A indústria também produz teoria? Contribuições de John T. Caldwell para os estudos do cinema e da televisão
}

\section{Ludmila Moreira Macedo de Carvalho}

Doutora; Universidade Federal do Recôncavo da Bahia, Santo Amaro da Purificação, BA, Brasil lud2046@gmail.com

\section{Elva Fabiane Matos do Valle}

Doutoranda; Universidade Federal da Bahia, Salvador, BA, Brasil

elvabr@gmail.com

\begin{abstract}
Resumo
O artigo procura apresentar as contribuições do pesquisador norte-americano John T. Caldwell para os estudos contemporâneos de cinema e televisão. Em diversas de suas obras, Caldwell aponta que a distância entre o pensamento analítico produzido nos ambientes acadêmicos e as práticas autorreflexivas dos trabalhadores no campo da produção audiovisual pode ser menor do que se pensa. Com efeito, o autor advoga que a observação das práticas autorreflexivas e autoconscientes dos trabalhadores em posições consideradas mais técnicas, e supostamente menos criativas, traria importantes contribuições para o pensamento teórico sobre a indústria do audiovisual. $\mathrm{O}$ artigo procura explorar, num primeiro momento, os conceitos de 'teoria industrial' e de 'práticas reflexivas abaixo-da-linha' desenvolvidos pelo autor. Num segundo momento, procuraremos averiguar de que modo as contribuições metodológicas das reflexões propostas por Caldwell nos permitem pensar questões de estilo em obras do cinema e da televisão.
\end{abstract}

\section{Palavras-chave}

Cinema. Televisão. Teoria industrial. John T. Caldwell. 


\section{Introdução}

Onde se localiza a teoria do audiovisual no mundo contemporâneo? Quem efetivamente produz teoria sobre o cinema e a televisão: os acadêmicos? Os realizadores? Os grupos de fãs? Os especialistas nos meandros do mundo da produção? Estas provocadoras indagações aparecem no artigo Screen studies and industrial 'theorizing' (CALDWELL, 2009), do pesquisador norte-americano John T. Caldwell - publicado, não por acaso, na revista Screen, um dos mais prestigiosos e respeitados periódicos acadêmicos de estudos de cinema e audiovisual ${ }^{1}$. Como um agente social que possui passagem tanto no campo acadêmico - como autor, professor e pesquisador - quanto no campo da produção - como produtor e diretor de dois documentários ${ }^{2}$-, Caldwell defende a ideia de que as relações entre o pensamento analítico produzido nos ambientes acadêmicos e as práticas autorreflexivas dos trabalhadores no campo da produção audiovisual possuem mais pontos de conexão do que de distanciamento.

Ainda que, a princípio, pareça que o discurso centrado nos textos dos teóricos e as práticas organizadas por fatores tecnológicos, econômicos, políticos e sociais dos produtores não se misture, para o autor ambos se preocupam com o essencial da troca estética: para os produtores o termo é conteúdo; para os acadêmicos a palavra é "texto" (CALDWELL, 2003). Tendo isso em vista, este artigo procura explorar as contribuições do pesquisador a respeito das complexas relações entre teoria e prática nos estudos de cinema e televisão, considerando, a princípio, os conceitos de teoria industrial e de práticas reflexivas abaixo-da-linha desenvolvidos por ele. Num segundo momento, procuraremos averiguar de que modo as contribuições metodológicas das reflexões propostas pelo autor nos permitem pensar questões de estilo em obras do cinema e da televisão.

\section{Teoria acadêmica e teoria industrial}

Caldwell (2009) defende que a teoria do audiovisual, ao contrário do que possa parecer no senso comum, não está confinada apenas ao ambiente acadêmico ou intelectual.

\footnotetext{
${ }^{1}$ Criada na década de 1950, a revista Screen foi responsável pela publicação de artigos fundamentais na história das teorias do cinema, tais como o seminal artigo de Laura Mulvey, Prazer visual e cinema narrativo, publicado em 1975.

2 São eles Freak Street to Goa: Immigrants on the Rajpath, de 1989, sobre os padrões migratórios de 'hippies' na India e no Nepal, e Rancho California (Por Favor), de 2002, sobre abrigos para migrantes indígenas no sul da Califórnia.
} 
Se consideramos teoria como "[...] questões que tentam definir o que seja o cinema/a televisão ou que debatem a respeito do que seria a qualidade no cinema/na televisão." (CALDWELL, 2009, p. 168, tradução nossa), então os/as trabalhadores/as do campo da produção audiovisual, que inclui desde os/as realizadores/as ${ }^{3}$ (diretores/as, roteiristas, atores/atrizes, produtores/as) até os/as técnicos/as e os/as especialistas nos bastidores, produzem teoria regularmente, posto que questões de fundo ontológico, analítico e/ou estético costumam aparecer com frequência nas sessões de debate após exibições ou em festivais, entrevistas, comentários, extras de DVDs, making-ofs, fóruns de discussão online ou visitas guiadas aos estúdios de cinema e televisão, para citar apenas alguns exemplos. Segundo o autor, “[...] a teoria da indústria pode se assemelhar às formas mais contemporâneas de 'desconstrução' analítica.” (CALDWELL, 2009, p. 168, tradução nossa).

Não se pode ignorar, portanto, que o campo do audiovisual possui práticas reflexivas, ou seja, está constantemente avaliando, analisando e teorizando a respeito de suas próprias práticas. Muitos/as dos/as trabalhadores/as deste campo de produção estão constantemente refletindo, analisando criticamente, discutindo e produzindo discursos sobre o que fazem. Na verdade, não apenas este tipo de autoanálise ou autorreflexão industrial existe como ela tem cada vez mais deixado o status de paratexto secundário para se tornar, ela mesma, obra principal e objeto tanto de apreciação quanto de análise. "Em algum nível”, diz Caldwell (2009),

[...] a teoria das indústrias do cinema, da televisão e das novas mídias, e as centenas de milhares de trabalhadores e profissionais nelas envolvidos, apequenam as restritas análises cuidadosamente construídas pelos acadêmicos e cautelosamente reproduzidas pelos estudantes de pósgraduação. (CALDWELL, 2009, p. 168, tradução nossa).

Além disso, estas reflexões possuem cada vez mais relevância, visibilidade e influência mesmo nos ambientes tradicionalmente acadêmicos. Neste sentido, o que significa produzir teoria a respeito de um campo dessa natureza? Qual o lugar das pesquisas acadêmicas neste complexo cenário?

\footnotetext{
${ }^{3}$ A título de esclarecimento, informamos que por tratarmos neste artigo de agentes sociais em posições empíricas, e não de entidades abstratas, optamos intencionalmente por mencionar os artigos nos gêneros feminino e masculino ao nos referirmos às/aos agentes no campo da produção audiovisual. Esta opção tem por objetivo ressaltar a importância de se considerar que tais posições são ou podem ser ocupadas tanto por homens quanto por mulheres.
} 
De certo modo, a ideia de que os/as agentes envolvidos/as na produção das obras possuem reflexões críticas e teóricas sobre seus fazeres artísticos não é propriamente uma novidade, sendo historicamente bem aceita nos círculos acadêmicos. Muitos diretores consagrados, a exemplo de François Truffaut, Jean-Luc Godard, Sergei Eisenstein entre outros, foram autores de pensamentos sistemáticos não apenas sobre suas próprias obras mas também sobre o cinema de modo geral. A alcunha teorias dos cineastas, popularizada a partir do livro homônimo de Jacques Aumont (2004), constitui uma linha teórica validada dentro das teorias do cinema, com grupos de pesquisa, publicações e eventos científicos dedicados ao tema 4 . Tal abordagem considera "[...] a perspectiva teórica dos cineastas diante de seus atos artísticos criadores." (GRAÇA; BAGGIO; PENAFRIA, 2015, p. 21), ou seja, pretende refletir a partir de um diálogo próximo com o discurso produzido pelos/as cineastas na mediação com as obras.

No entanto, é importante observar que a teoria dos cineastas tende a valorizar os/as agentes que Caldwell (2008) nomeia como acima-da-linha, ou seja, os/as diretores/as, roteiristas, produtores/as, atores/atrizes com posições de visibilidade pública e que costumam responder como responsáveis (ou ao menos corresponsáveis) intelectual e criativamente pelas obras que produzem. Por outro lado, os/as trabalhadores/as abaixoda-linha, aqueles/as que ocupam as funções mais técnicas - tais como operadores/as de câmera, iluminadores/as, assistentes de produção etc. - são comumente vistos/as como meros operários/as numa linha de produção industrial, ou seja, reprodutores/as de funções altamente compartimentadas e repetitivas que não possuem dimensão cognitiva ou input criativo em relação ao processo criativo da obra.

Esta visão a respeito das rotinas de trabalho e divisões de tarefas na indústria midiática implica, segundo Caldwell (2008; 2015), em dois grandes problemas. 0 primeiro deles é considerar que os/as trabalhadores/as menos visíveis ao olhar público não possuem suas próprias práticas reflexivas. Em entrevista publicada pelo periódico acadêmico Necsus, Caldwell se revela "[...] curioso pela rica e diversa forma de conversa de trabalho e teorização que ouvia enquanto fazia pesquisa de campo junto às comunidades de produção." (CALDWELL, 2015, doc. não paginado, tradução nossa, grifo nosso). Em outro momento, Caldwell (1995) comenta a respeito das reuniões de trabalhadores/as sindicalizados/as de emissoras de televisão, onde editores/as, operadores/as de câmera e fotógrafos/as citam

\footnotetext{
${ }^{4}$ Como exemplos no Brasil, podemos citar o Seminário Temático Teorias dos Cineastas presente no Congresso da Sociedade Brasileira de estudos de cinema e audiovisual (SOCINE) desde 2015, e o Grupo de Trabalho Teorias dos Cineastas da Associação dos Investigadores da Imagem em Movimento (AIM).
} 
Godard e analisam minuciosamente o material produzido por eles/as e por seus pares. "Essas não são o tipo de referências que a alta teoria espera encontrar no dia-a-dia de trabalho da indústria televisiva." (CALDWELL, 1995, p. 75, grifo do autor, tradução nossa). Caldwell (1995) conclui, portanto, que o alto grau de autorreflexividade e autoconsciência do meio midiático não é privilégio de seus/suas agentes mais reconhecidos/as, sendo compartilhado até mesmo por aqueles/as nas funções mais técnicas.

O segundo problema é que, segundo o pesquisador, há uma relação inversamente proporcional entre a posição dos/as trabalhadores/as no campo e a credibilidade de seus discursos; ou seja, quanto mais reconhecidos e visíveis ao olhar público, menos espontâneos e mais dirigidos são seus discursos. Segundo Caldwell (2008), é preciso ter sempre em mente o fato que o discurso analítico produzido muito proximamente das fontes interessadas “[...] é sempre gerenciado [e o] conhecimento sobre a indústria, adquirido seja através de documentação industrial ou entrevistas pessoais, é usualmente altamente codificado." (CALDWELL, 2008, p. 2, tradução nossa). Um dos problemas enfrentados pelos pesquisadores é o fato de que tanto os/as agentes individuais quanto as instituições possuem cada vez mais consciência da narrativa que são capazes de criar acerca de si mesmos/as e das obras que produzem e exibem, transformando esses discursos e materiais em verdadeiras comodidades no vasto universo multi e transmídia.

Pesquisadores, sobretudo aqueles preocupados com os estudos do campo da produção, frequentemente se veem assoberbados pela quantidade de discurso produzido pela própria indústria. No entanto, ao mesmo tempo em que se possui cada vez mais informação sobre os bastidores da produção artística, é preciso lembrar que essa informação é propriedade das instituições que a produzem e, muitas vezes, servem a propósitos comerciais. 0 que fazer, então, com essas informações? Ignorá-las por suas motivações comerciais e/ou interesses enviesados seria não apenas ingênuo como também pouco inteligente da parte dos acadêmicos. Não se pode ignorar que as disputas interpretativas no campo da teoria alimentam as práticas tanto quanto, inversamente, o discurso textual oriundo do campo da produção interfere no discurso acadêmico 5 . Deixar de considerar a importância das práticas e dos contextos de produção na reflexão sobre as obras é tão perigoso academicamente quanto confiar cegamente nelas, correndo-se o risco

\footnotetext{
${ }^{5}$ Caldwell (2009) aponta também que muitos/as dos/as realizadores/as atuantes no mercado hoje em dia possuem formação acadêmica, uma significativa alteração no perfil dos/as trabalhadores/as deste campo.
} 
de fugir de uma armadilha metodológica (confiar cegamente nos textos) apenas para cair em outra (confiar cegamento nos discursos dos/as realizadores/as).

A solução proposta por Caldwell (2008) está em empreender uma espécie de inversão na ordem tradicional com que estes discursos são coletados e analisados, através do que ele chama de textos profundos (deep texts), ou seja, as práticas culturais que falam mais do que os discursos explícitos e autoconscientes dos/as agentes mais reconhecidos/as. Segundo Caldwell (2008) o discurso e as práticas culturais produzidas pelos/as trabalhadores/as que ocupam as funções mais técnicas e, por isso mesmo, invisíveis ao olho público, tendem a oferecer novas e interessantes maneiras de abordar o fenômeno. Ao contrário dos teóricos, os/as realizadores/as

[...] raramente elaboram sistematicamente questões [a respeito da linguagem audiovisual] de maneira escrita ou falada. Ao contrário, essa forma de discussão teórica está embutida no universo do trabalho e se manifesta através das ferramentas, máquinas, artefatos, iconografias, modos de trabalho, rituais profissionais e narrativas que os trabalhadores do campo do cinema fazem circular e encenam nas suas subculturas. (CALDWELL, 2008, p. 26, tradução nossa).

Caldwell (2008) reconhece, portanto, que os tipos de reflexões empreendidas pelos/as agentes no campo da produção diferem bastante do que normalmente se considera como "teoria" no campo acadêmico.

Teorias do cinema e da comunicação [...] tendem a valorizar argumentos teóricos baseados na sua eficácia em produzir um discurso que seja sistemático, lógico e/ou convincente na tarefa de explicar como o cinema/a mídia funciona ou produz sentido. (CALDWELL, 2008, p. 18, tradução nossa).

Por outro lado, as práticas teóricas oriundas do campo da produção não obedecem aos mesmos critérios de rigor sistemático ou lógica racional, apresentando-se, muitas vezes, maleável ou até mesmo contraditória a depender do contexto em que se encontra. 0/a mesmo/a agente - um/a roteirista, por exemplo - pode falar a respeito de sua própria prática de um modo completamente técnico e mecânico para seus pares, e citar referências artísticas e intelectuais ao falar para estudantes de um curso superior em cinema. 
Caldwell (2008) enumera seis modos de caracterizar as disposições autorreflexivas oriundas das práticas industriais: (1) instrumental e indutiva, (2) ecumênica e eclética, (3) não-intencional ou obliterada, (4) redutora e patenteada, (5) instantânea ou preemptória, e finalmente (6) senso comum. 0 discurso instrumental e indutivo é aquele que reveste a prática de decisões técnicas e racionais, orientadas a resolver problemas práticos; como exemplo, Caldwell (2008) traz a fala do diretor de fotografia Michael Chapman que resume o seu ofício dessa forma: "[...] o trabalho do diretor de fotografia é dizer aos atores para onde olhar." (CALDWELL, 2008, p. 15, tradução nossa). Ao mesmo tempo, a resolução desses problemas práticos envolve decisões artísticas que, muitas vezes, são caracterizadas de forma bastante eclética:

Os trabalhadores da produção tendem a ser ecumênicos, pois estão dispostos a usar qualquer solução (qualquer tradição estética ou perspectiva teórica), desde que forneça a ferramenta para superar algum obstáculo ou uma chave que se encaixe no filme. (CALDWELL, 2008, p. 19, tradução nossa).

Tais decisões artísticas são frequentemente desenvolvidas e reproduzidas a partir da prática diária do ofício, de um modo intuitivo e até mesmo pouco intencional. Numa relação inversa ao discurso dos/as agentes acima-da-linha, que em geral tendem a assumir uma postura de autoridade intelectual e intencionalidade em relação às suas decisões criativas, os/as agentes abaixo-da-linha frequentemente descrevem suas decisões modestamente como resoluções de problemas práticos para atender às demandas de diversas instâncias (diretores/as, produtores/as, etc.). A autorreflexão industrial também é, segundo Caldwell (2008), redutora e patenteada:

\footnotetext{
Não importa quão complicada, intimidadora ou opressiva seja a imagem dos bastidores de um estúdio de filmagens ou de um departamento de efeitos de imagens geradas por computador (CGI) que pode aparecer em um making-of, os DVDS que incluem essas informações normalmente explicam ou reduzem o empreendimento inteiro usando noções razoavelmente arcaicas ligadas, por exemplo, à persistente e jocosa "mágica" dos artistas e alquimistas medievais. (CALDWELL, 2008, p. 21, tradução nossa).
} 
Esse reducionismo, que transforma o trabalho de cientistas e técnicos/as altamente especializados/as numa espécie de mágica genérica está diretamente relacionado aos segredos técnicos e patentes das instituições cuidadosamente guardados por contratos de exclusividade e de não-divulgação. Um outro traço da teoria industrial, segundo Caldwell (2008), é o fato que esse processo reflexivo tende a ser instantâneo, ou seja, produzido concomitantemente (quando não antes) ao desenvolvimento da obra, ao contrário da reflexão acadêmica que, na maioria das vezes, considera o fenômeno já realizado e a obra concluída. Por fim, estas características do discurso dos/as trabalhadores/as da indústria midiática a respeito de suas práticas reproduzem o senso comum, ou seja, a ideia de que há pouca ou nenhuma contribuição criativa ou teórica em seus ofícios, e que há pouca relevância cultural nos projetos que empreendem.

O problema, para Caldwell (2008), não está na ideia de que tais reflexões meramente reproduzem o senso comum, mas sim na visão de que, ao fazer isso, elas deixam de ser relevantes ou deixam de ser reflexões. Ao contrário, para o autor elas são simplesmente reflexões-tornadas-práticas: "Cineastas [...] tomam decisões estéticas, colocam ideias teóricas em prática e fazem distinções críticas em suas tarefas e mundos de trabalho." (CALDWELL, 2008, p. 14, tradução nossa). Esta abordagem aproxima-se do que teóricos como David Bordwell e Noel Carroll (2012) chamam de "teoria nível médio", ou seja, uma metodologia analítica que, ao contrário das teorias acadêmicas que parecem partir de grandes problemas ou categorias genéricas para só então verificá-las nas obras efetivas, parte das práticas delimitadas, localizadas em obras específicas - e do senso comum, por que não? - para verificar como se transformam historicamente em categorias analíticas ou teóricas. "Ao contrário do que pensa a Grande Teoria, ser empírico não exclui ser teórico." (BORDWELL; CARROLL, 2012, p. 27).

Talvez seja justamente nessa proposição metodológica que resida a maior contribuição da abordagem de Caldwell $(1995,2008,2009)$ para os estudos do cinema e da televisão. Sua proposta inverte a relação teórica que se estabelece da produção discursiva do alto para baixo, procurando verificar como se produz teoria industrial de baixo para cima. No livro Production Culture (2008), Caldwell propõe um método de análise culturalindustrial integrando análise textual com pesquisa econômica, institucional e etnográfica, na tentativa de diálogo entre texto e contexto. Caldwell (2008) parte da hipótese que as indústrias do cinema e da televisão podem ser compreendidas como culturas ou comunidades sociais em seu próprio direito - ou seja, ao invés de (ou melhor, além de) 
estudar a relação das mídias com a sociedade mais ampla onde estão inseridas, ele se interessa em estudar as mídias como um microcosmo social, dotadas de todos os processos simbólicos e práticas sociais coletivas que outras culturas usam: construções identitárias, meios de perpetuar a si mesma e a seus interesses etc.

Neste sentido, seu estudo se aproxima dos estudos sociais que integram análise microssociológica cultural (localizada, específica) e a análise de estruturas macrossociológicas econômicas e políticas. Subscreve também a uma metodologia antropológica de ida ao campo, considerando a cultura menos como mecânica e mais como semântica, ou seja, tratando-a como texto, que pode e deve ser interpretado assim como as obras. "A cultura de um povo é um conjunto de textos, eles mesmos um conjunto que o antropólogo se esforça para ler sobre os ombros daqueles a quem os discursos pertencem." (GEERTZ, $1990^{6}$ apud CALDWELL, 2008, p. 5, tradução nossa).

Para tanto, o autor ressalta que é importante verificar as informações de quatro registros ou modos de análise interligados: a análise textual das obras; entrevistas com os/as trabalhadores/as no campo da produção; observação etnográfica do campo e dos espaços de produção; e análise econômica-industrial (CALDWELL, 2008), analisando os materiais que são:

a) totalmente incorporados, como as fitas demo, sessões de pitching, manuais internos de produção, comportamento de trabalho no set, entre outros;

b) semi-incorporados, como os kits de imprensa, materiais de divulgação e eventos corporativos;

c) divulgados publicamente, como os extras em DVDs, making ofs, websites, convenções de fãs realizadas pelo estúdio e aparições públicas em programas jornalísticos. (CALDWELL, 2008, p. 346).

Todo esse material, quando coletado, permite acesso às formas variadas e complexas que a indústria aborda, discutindo, analisando e contestando as ideias sobre a natureza, o significado e as práticas do fazer televisão/cinema. Desta forma, propõe-se um olhar para além dessa oposição - teórica, artificial - entre o "texto-tela" e o "contexto-indústria", considerando, então, as formas como a associação das tecnologias, dos discursos, das interações, das práticas industriais e das decisões estéticas fazem sentido em conjunto.

\footnotetext{
${ }^{6}$ GEERTZ, Clifford. Deep play: notes on a Balinese cockfight. In: MUKERJI, Chandra; SCHUDSON, Michael (ed.). Re-thinking popular culture. Berkeley: University of California Press, 1990. Apud Caldwell (2008).
} 


\section{Tecnologia, estilo, modos de produção}

Consideremos, a partir deste ponto, o modo como Caldwell aborda a complexa relação entre avanços tecnológicos nas ferramentas de produção e as marcas estilísticas visíveis nas obras. É importante mencionar que as breves reflexões sobre as obras descritas a seguir não se pretende exaustiva do ponto de vista analítico; funcionam, mais, como ilustração dos procedimentos metodológicos do autor em questão e de sua compreensão abrangente do estilo como ferramenta de análise. Estilo, nesse caso, define-se como o modo com que os materiais da linguagem audiovisual - que compreende desde o que se chama de mise-enscène, ou seja, a organização e disposição dos elementos para a câmera, o cenário, o figurino, a iluminação e o movimento e atuação dos atores, até os usos da câmera, a montagem e a trilha sonora - são utilizados sistemática e significativamente de modo expressivo pelos criadores da obra para atingir um determinado efeito (BORDWELL, 2008).

Em sua obra Televisuality (CALDWELL, 1995), Caldwell desenvolve uma interessante reflexão a respeito do que chama de televisualidade, o estilo próprio da linguagem televisiva. Segundo o autor, antes da década de 1980 os programas televisivos possuíam o que ele chama de "grau zero" de estilo, ou seja, pouco (ou quase nenhum) movimento de câmera, ênfase nos diálogos, iluminação e cenários sem função expressiva ou, nas palavras de Bordwell (2008), com função denotativa. "Em certo sentido, é uma produção narrativa sem pretensão, projetada para apresentar o máximo de narrativa tão eficiente quanto o orçamento, o tempo e a tecnologia permitirem." (BUTLER, 2010, p. 26, tradução nossa).

Observando, por exemplo, um dos gêneros mais populares e duradouros da televisão norte-americana - as séries de detetive ou investigativas -, é possível perceber este movimento. Segundo Mareike Jenner (2016), no livro American TV Detective Dramas, nos anos 1970 as séries de detetive em geral apresentavam pouca inovação estética, mantendo o foco na narrativa e nos métodos de detecção, ou seja, na variedade de percursos possíveis para alcançar a solução do crime7. Não por acaso, Jenner (2016) aponta um crescimento nesta época das séries detetivescas procedurais, ou seja, séries estruturadas a partir de um universo ficcional fixo - como, por exemplo, a rotina da delegacia de polícia de Los Angeles em Columbo [NBC 1971-2003] -, com episódios relativamente autônomos em que um novo

\footnotetext{
${ }^{7}$ A autora aponta que a fórmula narrativa das séries investigativas, bastante influenciada pela literatura policial, apresenta basicamente dois métodos dedutivos: o primeiro se aproxima do método indutivo-dedutivo de Sherlock Holmes, o conhecido detetive analítico; o segundo faz parte do subgênero hardboiled, que se fundamenta mais em instinto, uso de violência para se obter respostas, com o private investigator (PI) durão. (JENNER, 2016).
} 
crime era apresentado, investigado e solucionado a cada semana. "A única coisa que mudava de semana para semana eram as histórias, roteiros e elenco convidado." (JENNER, 2016, p. 95, tradução nossa).

A partir de 1980 o mercado televisivo norte-americano passou por importantes mudanças nos paradigmas conceituais e ideológicos de sua forma de apresentação, atingindo o estilo definido pelo autor como exibicionismo visual: os produtos televisivos passaram a apresentar-se cada vez mais visuais e experimentais do ponto de vista estilístico, marcados pelo excesso no uso de efeitos gráficos, sobreposições de imagens, técnicas de montagem não-linear, combinação de imagem e texto e outros elementos hipervisuais que se tornaram naturalizados a partir deste momento. A série Miami Vice [NBC, 1984-1989], por exemplo, tornou-se conhecida por misturar o procedural detetivesco com inúmeros recursos visuais e sonoros que remetiam ao estilo hipervisual da MTV e dos videoclipes ${ }^{8}$.

[...] a televisão passou de uma estrutura que abordava a transmissão primariamente como uma forma de retórica baseada principalmente na palavra e na emissão, com todas as questões que esses termos sugerem, para uma mitologia baseada na visualidade, e para uma estrutura e estética baseadas em extrema autoconsciência de estilo. (CALDWELL, 1995, p. 4, tradução nossa).

De fato, essa autoconsciência a respeito do estilo visual tornou-se tão evidente que, segundo o autor, estilo deixou de ser a forma, ou o veículo para a transmissão do conteúdo dos programas, para tornar-se o próprio significante: "televisão veio para ostentar e exibir estilo" (CALDWELL, 1995, p. 5, tradução nossa). Notadamente, à medida em que a televisão passou a exibir mais estilo, os realizadores passaram a buscar marcas de identidade que diferenciassem suas obras num ambiente cada vez mais competitivo. Estilo, nesse sentido, passa a ser não apenas marca de expressividade das obras como também marca de individualização das mesmas. "Muitas das mais notáveis séries policiais desde a década de 1980 se basearam floreios estilísticos a fim de se diferenciarem da crescente confusão de programação disponível via cabo, satélite ou tecnologia de vídeo doméstico." (NICHOLSPETHICK, 2012, p. 34).

A partir dos anos 2000, torna-se cada vez mais fácil perceber como as inovações no estilo visual repercutem também na narrativa das séries, criando novas formas de

\footnotetext{
8 "Miami Vice foi originalmente proposta [para a emissora] como 'policiais MTV'." (JENNER, 2016, p. 102, tradução nossa).
} 
apresentar o gênero. É o caso, por exemplo, do estilo hiper-realista de séries como CSI: crime scene investigation [CBS, 2000-2015] e suas franquias CSI Miami [2002-2012] e CSI NY [2004-2013], em que efeitos especiais são utilizados para mostrar, por exemplo, a trajetória de uma bala atravessando um corpo humano ou detalhes microscópicos das análises das evidências numa cena de crime. 0 uso destes e de outros recursos estilísticos se relaciona diretamente com a proposta da série de deslocar o ponto de vista do processo investigativo da figura misteriosa do detetive para a dos técnicos forenses e da investigação baseada em evidências científicas. Outro exemplo é a série 24 [FOX, 2001-2010], que utilizou inserções gráficas e o recurso da tela dividida para ressaltar o efeito de tempo real da narrativa, em que cada episódio narra eventos ocorridos em uma hora na vida de um agente contraterrorista do governo norte-americano. Neste caso, o efeito está relacionado a uma imersão do espectador no universo de um agente que precisa tomar decisões a respeito dos casos que investiga em frações de segundo, muitas vezes recorrendo a métodos questionáveis como tortura e violência.

Caldwell (1995) enfatiza que, para melhor compreender este fenômeno, é preciso verificar não apenas as condições e precedentes ideológicos, artísticos e econômicos, mas também as condições industriais, materializadas através do surgimento de novos aparatos de manipulação eletrônica da imagem e as mudanças nos modos de produção decorrentes destas inovações tecnológicas ${ }^{9}$. 0 surgimento e adoção de novas tecnologias gera debates artísticos e estilísticos e, por isso, essas novas ferramentas devem ser consideradas não apenas como atividade empresarial (redução de custos, aumento de qualidade, inovação no setor), mas também como parte do processo coletivo conceitual e estético de produção. Segundo Caldwell (1995), “[...] as novas ferramentas não influenciam apenas o que os espectadores veem nas imagens, mas também tem uma influência profunda sobre o modo como as imagens são construídas, alteradas e exibidas." (CALDWELL, 1995, p. 77, tradução nossa).

\footnotetext{
${ }^{9}$ Dentre as inovações técnicas que mudaram a forma de compor as imagens televisivas estão, por exemplo, o vídeo assistente ou video assist, sistema que permite à equipe de filmagem acompanhar num monitor de vídeo a imagem da cena que está sendo filmada. Antes disso, a imagem captada pela câmera era acompanhada apenas pelo operador de câmera, sendo que o diretor e o restante da equipe precisavam esperar o fim das gravações do dia para assistir às projeções. Este procedimento era não apenas dispendioso, como também implicava numa certa falta de controle em relação ao que efetivamente foi captado pela câmera. 0 vídeo assistente permitiu maior precisão na composição e filmagem dos planos, economizando tempo e dinheiro - objetivos claramente comerciais -, mas também mudando as práticas de produção, as relações de trabalho e autoria dentro do set de filmagens, visto que um grupo maior de agentes (incluindo atores, assistentes e outros trabalhadores) passou a acompanhar e dar palpites sobre como compor a imagem. Esta tecnologia tornou todos da equipe altamente conscientes e preocupados com uma função que, antes, era responsabilidade apenas da comunicação entre diretor e operador de câmera (CALDWELL, 1995, p. 79).
} 
O autor defende, portanto, que os processos de seleção do aparato técnico de filmagem não acontecem de forma meramente arbitrária, técnica e/ou comercial, trazendo significados e efeitos estéticos importantes para as obras (CALDWELL, 2008); uma vez que, como comenta Pareyson (1993), o processo de criação começa nas possibilidades de escolha do material. Nesse sentido, as ferramentas de produção operam além do mero instrumentalismo segundo o qual normalmente são caracterizadas. Para o pesquisador, é no mínimo curioso que os acadêmicos não costumem considerar a importância das novas tecnologias para os estilos artísticos desenvolvidos a partir destas mudanças, uma vez que as condições de produção - sejam elas técnicas, sociais ou econômicas - influenciam diretamente na materialidade das obras (CALDWELL, 2009).

A abordagem dada ao estilo por Caldwell (2009) aproxima-se bastante ao que David Bordwell (2008) define a partir do esquema problema-solução: cada decisão artística tomada por um realizador (ou um técnico) no momento da produção corresponde a uma resposta específica a um problema específico, e tais respostas são informadas não apenas pelas intenções artísticas ou habilidades estéticas dos agentes, mas também pelo conjunto de materiais, técnicas e práticas estilísticas disponíveis no momento da produção. Bordwell (2008) refere-se ao conceito de schemata (esquema) inicialmente proposto pelo historiador da arte Ernst Gombrich (2007) para referir-se aos padrões estilísticos de representação de que um artista dispõe no processo de produção. Isso quer dizer que, ao fazer uma obra, o artista não parte simplesmente do zero, mas tem como ponto de partida esquemas estilísticos que dependem, entre outros fatores, dos materiais disponíveis, das inovações técnicas que se apresentam naquele momento, e dos diálogos estabelecidos com outras obras. A escolha, ou solução que cada artista em particular dá para o encargo que assume implica no descarte de todas as outras soluções possíveis; trata-se, portanto, de uma escolha que dialoga não apenas com as intenções do artista e suas habilidades e limitações técnicas particulares, mas também com a tradição das escolhas da qual dispôs naquele momento histórico e com a qual sua obra, uma vez pronta, voltará a dialogar.

\section{Considerações finais}

Ao longo deste artigo, procuramos explorar a premissa do autor John T. Caldwell (2008; 2009) de que as práticas dos/as agentes envolvidos/as no campo da produção, sobretudo aqueles/as menos visíveis ao olhar público, não somente possuem formas 
teóricas como tais formas podem trazer contribuições consideráveis para as pesquisas no campo do cinema e da televisão. Nesta perspectiva, até mesmo os estudos mais imanentes e formais das obras se beneficiariam de um exame cuidadoso das tecnologias, práticas de trabalho e discursos que fazem essas obras.

Procuramos demonstrar de que modo a metodologia integrada proposta pelo autor torna-se possível através do exemplo de uma de suas múltiplas variáveis: as relações entre as tecnologias, os modos de produção e as escolhas estilísticas visíveis nas obras. À guisa de conclusão, consideramos importante salientar que, para Caldwell (2009), tal relação não é de natureza simples ou determinista - ou seja, não se trata de dizer que o estilo televisivo se tornou excessivo em decorrência das inovações tecnológicas, mas sim de reconhecer esta variável como importante parte do processo de criação. 0 desenvolvimento de novas tecnologias vem sempre acompanhado de um discurso estético:

0 valor crescente do estilo excessivo na rede de horário nobre e na televisão a cabo durante a década de 1980 não pode simplesmente ser explicado apenas por referência a um ponto de vista estético. Em vez disso, a ênfase estilística que surgiu durante este período resultou de uma série de tendências e mudanças inter-relacionadas: no modo de produção da indústria, na prática de programação, na audiência e suas expectativas, e de uma crise econômica na rede de televisão. Essa confluência de práticas materiais e pressões institucionais sugere que o estilo televisivo foi o sintoma de um período muito mais amplo de transição nos meios de comunicação e na cultura americana. (CALDWELL, 1995, p. 5, tradução nossa).

Deste modo, consideramos instigante a perspectiva apresentada pelo pesquisador de que os aparatos técnicos também "pensam", no sentido de que "[...] todas estas ferramentas - sejam elas analógicas ou digitais, mecânicas ou computadorizadas expressam e facilitam a inteligência através de seus designs e usos." (CALDWELL, 2008, p. 151, tradução nossa). Aproximando-se da noção de uso dessas ferramentas como performances culturais, torna-se importante pensar que a escolha de uma determinada tecnologia para a realização de uma determinada tarefa (ou resolução de um determinado problema estilístico) conota diferentes significados dentro e fora dos sets: o uso de uma câmera steadicam, por exemplo, provoca associação com as grandes e caras produções de cinema, com a ideia de movimento fluido e alto grau de controle da mise-en-scène; já o uso de uma câmera na mão provoca associações com diferentes códigos culturais, como a ideia 
de realismo documental, com a tentativa de captar movimentos inesperados em cenários reais, com a estética do cinema moderno etc. Estes modos diferem não apenas no aspecto estilístico do produto final que chega ao espectador, mas também nas ideias e performances culturais que se estabelecem, cultivam-se e se reforçam no universo do trabalho no campo da produção (CALDWELL, 2008, p. 153).

Esta observação nos remete de volta à perspectiva metodológica do autor de considerar o universo do campo da produção na indústria do audiovisual como uma cultura cujas práticas também podem (e devem) ser interpretadas. Neste sentido, Caldwell (2008) argumenta que analisar não somente o discurso, mas também as práticas, as escolhas técnicas e artísticas, os processos de autorreflexão dos/as agentes produtores/as, pode ser tão importante para a pesquisa quanto analisar as obras nas telas. 0 antagonismo entre "texto-tela" e "contexto-indústria" muitas vezes colocado pelo campo dos estudos do cinema e da televisão é artificial e não permite, por exemplo, verificar o que existe de empírico nas obras como práticas, e o que existe de texto, de estilo, no discurso dos/as trabalhadores/as da indústria do audiovisual.

[...] os estudiosos devem olhar para além da separação padrão entre "teoria" do filme e "trabalho" do filme, e considerar como as práticas industriais, tecnologias, discursos e interações também envolvem análise crítica, elaboração teórica, e construção de sentido estético. (CALDWELL, 2008, p. 7).

\section{Referências}

AUMONT, Jacques. As teorias dos cineastas. Campinas: Papirus, 2004.

BORDWELL, David. Figuras traçadas na luz: a encenação no cinema. Campinas: Papirus, 2008.

BORDWELL, David; CARROLL, Noël (ed.). Post-theory: reconstructing film studies. Wisconsin: University of Wisconsin Pres, 2012.

BUTLER, Jeremy G. Television Style. New York: Routledge, 2010.

CALDWELL, John T. Televisuality: style, crisis, and authority in American. New Brunswick: Rutgers University Press, 1995. 
CALDWELL, John T. Second-shift media esthetics: programming, interactivity and user flows. In: EVERETT, Anna; CALDWELL, John T. (ed.). New Media: theories and practices of digitextuality. New York: Routledge, 2003. p. 127-144.

CALDWELL, John T. Dredging, drilling, and mapping television's swamps: an interview with John T. Caldwell on the 20th anniversary of 'Televisuality'. [Entrevista cedida a] Markus Stauff. NECSUS, 16 nov. 2015. Disponível em: https://necsus-ejms.org/dredging-drillingmapping-televisions-swamps-interview-john-caldwell-20th-anniversary-televisuality/. Acesso em: 28 abr. 2019.

CALDWELL, John T. Production Culture: Industrial Reflexivity and Critical Practice in film and television. Durham: Duke University Press, 2008.

CALDWELL, John T. Screen studies and industrial 'theorizing'. Screen, Glasgow: Oxford University Press, v. 50, n. 1, p. 167-179, 2009.

GOMBRICH, Ernst. Arte e ilusão: um estudo da psicologia da representação pictórica. São Paulo: Martins Fontes, 2007.

GRAÇA, André Rui; BAGGIO, Eduardo Tulio; PENAFRIA, Manuela. Teoria dos cineastas: uma abordagem para a teoria do cinema. Revista Científica da Faculdade de Artes do Paraná, Curitiba, v. 12, p. 19-32, 2015.

JENNER, Mareike. American TV detective dramas: serial investigations. Londres: Palgrave, 2016.

NICHOLS-PETHICK, Jonathan. TV cops: the contemporary american television police drama. New York: Rutledge, 2012.

PAREYSON, Luigi. Estética: teoria da formatividade. Petrópoles: Vozes, 1993.

\title{
Does the Industry produce theory? John T. Caldwell's contributions to film and television studies
}

\begin{abstract}
This paper intends to explore John T. Caldwell's contribution to contemporary film and television studies. In several of his works, Caldwell points out that the distance between high theory produced in the academic field, in one hand, and the self reflexive practices of workers in the film and television industry, in the other hand, might be a lot smaller than first expected. The author argues that observing the self-reflective practices of
\end{abstract}


workers in the more technical positions might bring relevant contributions to film and television theories. The article seeks to explore, first, the concepts of 'industrial theory' and 'below-theline' reflective practices developed by the author. Further, we will explore the methodological contributions of Caldwell's reflections to the observation of matters of style in cinema and television.

\section{Keywords}

Film. Television. Industrial theorizing. John T. Caldwell.

Recebido em 01/05/2019

Aceito em 01/07/2019 